\title{
A Simple Procedure for Searching Pareto Optimal Front in Machining Process: Electric Discharge Machining
}

\author{
Ushasta Aich and Simul Banerjee \\ Mechanical Engineering Department, Jadavpur University, Kolkata 700032, India \\ Correspondence should be addressed to Ushasta Aich; ushasta@yahoo.co.in \\ Received 18 January 2014; Revised 28 May 2014; Accepted 29 May 2014; Published 26 June 2014 \\ Academic Editor: Nikos D. Lagaros
}

Copyright ( $) 2014$ U. Aich and S. Banerjee. This is an open access article distributed under the Creative Commons Attribution License, which permits unrestricted use, distribution, and reproduction in any medium, provided the original work is properly cited.

Optimum control parameter setting in complex and stochastic type processes is one of the most challenging problems to the process engineers. As such, effective model development and determination of optimal operating conditions of electric discharge machining process (EDM) are reasonably difficult. In this apper, an easy to handle optimization procedure, weight-varying multiobjective simulated annealing, is proposed and is applied to optimize two conflicting type response parameters in EDM-material removal rate (MRR) and average surface roughness ( $\mathrm{Ra}$ ) simultaneously. A solution set is generated. The Pareto optimal front thus developed is further modeled. An inverse solution procedure is devised so that near-optimum process parameter settings can be determined for specific need based requirements of process engineers. The results are validated.

\section{Introduction}

Electrical discharge machining (EDM) process is extensively used in the machining industry for the manufacture of mould, die, automotive, aerospace, and surgical components [1]. The material is removed in this process by the erosive action of spatially discrete and chaotic [2] high-frequency electrical discharges (sparks) of high power density between a tool electrode and the workpiece electrode with a dielectric fluid in the gap between them. In the EDM process, the material removal rate (MRR) and average surface roughness $(\mathrm{Ra})$ are two very important and conflicting response parameters of which process engineers are mostly interested. EDM process is complex and stochastic in nature and, therefore, modeling of it and determining the conditions for optimal machining performance are reasonably difficult.

Several researchers have proposed various methodologies for predicting and optimizing the performance of EDM process [3]. Lin et al. [4] carried out their experiment with orthogonal array $\left(\mathrm{L}_{9}\right)$ based design considering pulse on time $(100,150$, and $300 \mu \mathrm{s})$, duty factor $(0.3,0.5$, and 0.7$)$, and discharge current $(1.5,4.0$, and $6.0 \mathrm{~A})$ as control parameters and material removal rate, electrode wear ratio, and surface roughness as response parameters. They used SKD11 alloy steel as workpiece material, copper as tool electrode, and kerosene as dielectric fluid. Grey relational analysis and fuzzy based Taguchi method were separately applied on experimental data set and both gave same optimum result, that is, pulse on time: $300 \mu \mathrm{s}$, duty factor: 0.3 , discharge current: 6 A, MRR: $0.00598 \mathrm{~g} / \mathrm{min}$, electrode wear ratio: 2.81, and Ra: $2.05 \mu \mathrm{m}$.

J. L. Lin and C. L. Lin [5] employed grey-fuzzy logic on same experimental results obtained in [4]. Also, they have found the same optimal combination listed in [4].

Fuzzy based Taguchi method was also used by Tzeng and Chen [6] performing their experiment on SKD11 tool steel with $99.95 \%$ pure copper electrode. They added aluminum powder to dielectric kerosene with different concentrations (0.1, 0.3 , and $\left.0.5 \mathrm{~cm}^{3} / \mathrm{L}\right)$ and powder sizes $(1,10-20$, and $40 \mu \mathrm{m}) . \mathrm{L}_{18}$ orthogonal array of control parameters, namely, open circuit voltage $(120,230 \mathrm{~V})$, pulsed duration $(12,75$, and $400 \mu \mathrm{s})$, duty cycle $(33,50$, and $66 \%$ ), pulsed peak current $(12,18$, and $24 \mathrm{~A}$ for $33 \%, 8,12$, and $16 \mathrm{~A}$ for $50 \%$, and 6,9 , and $12 \mathrm{~A}$ for $66 \%$ duty cycle), regular distance for electrode lift (1, 6, and $12 \mathrm{~mm}$ ), and time interval for electrode lift $(0.6,2.5$, and $4.0 \mathrm{~s})$, was considered for DOE and electrode dimension was measured in each experimental run. Optimum combination for maximum dimensional precision 
was listed as open circuit voltage: $120 \mathrm{~V}$, pulsed duration: $12 \mu \mathrm{s}$, duty cycle: $66 \%$, pulsed peak current: $6 \mathrm{~A}$, regular distance for electrode lift: $12 \mathrm{~mm}$, time interval for electrode lift: $0.6 \mathrm{~s}$, powder concentration: $0.5 \mathrm{~cm}^{3} / \mathrm{L}$, and powder size: $40 \mu \mathrm{m}$.

Wang et al. [7] performed their experiments using graphite electrode and nickel base alloy workpiece. GA trained (for adjusting weight vectors) neural network modeling was adopted for MRR and Ra with on time, off time, peak current, voltage, compression, and gain as input variables. GenHunter multiobjective optimization technique was further applied to the trained model and optimum input factor settings and corresponding MRR and Ra were found. Their optimum results were on time: $25.49 \mu \mathrm{s}$, off time: $13.73 \mu \mathrm{s}$, peak current: $9.8 \mathrm{~A}$, voltage: $33.33 \mathrm{~V}$, compression: $37.76 \mathrm{~mm}$, gain: 28.04, MRR: $1038.58 \mathrm{~mm}^{3} / \mathrm{min}$, and Ra: $6.97 \mu \mathrm{m}$.

Su et al. [8] trained their experimental results (electrode: copper, workpiece: steel) by feedforward neural network with backpropagation learning algorithm and used GA for optimizing the trained model of MRR, tool wear ratio, and Ra. Pulse on time (1.5-2400 $\mu$ s in 24 steps), pulse off time $(1.5-2400 \mu \mathrm{s}$ in 24 steps $)$, high-voltage discharge current $(0.3,0.7$, and $1.0 \mathrm{~A})$, low-voltage discharge current (0-200 A), gap size, servo feed, jumping time (0.3-2.5 $\mathrm{s}$ in 16 steps), and working time $(0.3-10 \mathrm{~s}$ in 16 steps) were considered as control factors. They performed their experiments with rough, middle, and finish cut with 3 different machining areas $\left(1,4\right.$, and $\left.16 \mathrm{~cm}^{2}\right)$. Finally, a list of optimum results was given. In all of these works $[7,8]$, multiobjective problem was converted to single objective function for optimization.

Kuriakose and Shunmugam [9] applied nondominated sorting genetic algorithm (NSGA) for multiobjective optimization of WEDM responses (cutting velocity and surface finish on Ti alloy workpiece material) modeled by multiple linear regression analysis. They reported 36 solution points for optimum combination of responses with control factors (ignition pulse current $(8,16 \mathrm{~A})$, pulse off time $(4,6$, and $8 \mu \mathrm{s})$, pulse duration $(0.6,0.9$, and $1.2 \mu \mathrm{s})$, servo control reference mean voltage $(30,45$, and $60 \mathrm{~V})$, maximum servo speed variation $(29.28,58.56$, and $87.84 \mathrm{~mm} / \mathrm{min})$, wire speed $(4,6$, and $8 \mathrm{~m} / \mathrm{min})$, wire tension $(0.8,0.9$, and $1 \mathrm{~kg})$, and injection pressure (2, 3 , and 4 bar)) settings.

Mandal et al. [10] carried out their experiment using copper electrode on C40 steel with Rustlick EDM oil of grade EDM 30 and flushing pressure as $0.25 \mathrm{~kg} / \mathrm{cm}^{2}$. They used BPNN procedure to model the EDM process with pulse on time $(23-506 \mu \mathrm{s})$, pulse off time (23-186 $\mu \mathrm{s})$, and discharge current (4-18 A) as controllable machining parameters and adopted NSGA-II to optimize simultaneously the responses (MRR and tool wear). 100 points were obtained in their Pareto optimal set. However, the validation of Pareto optimal solution set, thus developed, was not reported in the above literatures [8-10].

Yang et al. [11] applied simulated annealing to counter propagation neural network (CPNN) model of EDM (electrode: copper, workpiece: steel, dielectric: kerosene) responses for optimization purpose. A comparison between BPNN and CPNN techniques was also reported. They considered MRR and $\mathrm{Ra}$ as the output parameters and source voltage $(80,160$, and $200 \mathrm{~V})$, discharge current (6, 16 , and $48 \mathrm{~A})$, pulse on time $(6.4,100$, and $800 \mu \mathrm{s})$, and pulse off time $(12.8,50$, and $400 \mu \mathrm{s})$ as control variables. Two objective functions one each for MRR and Ra were combined to a single one using weight vectors. Negative weight vector for MRR was used for this purpose though physical significance of considering negative MRR was not clearly discussed. Further, weight vectors did not equally influence the objective functions due to different range in the values of responses. Though they had reported 10 different optimal combinations obtained during various runs of the program, yet it was not explained that what factors were varied during different trials; otherwise, same settings of all factors with different initial starting point should be ended up to same results in each trial for a single objective optimization. Finally, a particular optimum result was highlighted for maximum MRR and minimum Ra. They also did not conduct any confirmation test.

Electrical discharge machining is a thermoelectric process and the chosen range of parameters influences the optimum settings substantially. The literature survey made so far reveals that a number of optimum combinations of conflicting EDM responses are feasible but there exists no specific procedure that could suggest what might be the possible setting of input parameters for a need based optimum/nearoptimum combination of responses. The present work aims at laying down a viable simple procedure towards that effect.

In the present work, therefore, electrical discharge machining process is statistically modeled using regression analysis with current setting, pulse on time, and pulse off time as the input parameters. An easy to handle optimization procedure, weight-varying multiobjective simulated annealing, is proposed and is applied to optimize two conflicting type response parameters in EDM-material removal rate (MRR) and average surface roughness (Ra) simultaneously. A solution set is generated. A Pareto optimal front thus obtained is further modeled as a continuous function so that applying an inverse solution procedure the control parameter setting can be found out for a specific need based machining performance.

\section{Weight-Varying Multiobjective Simulated Annealing}

Optimization technique based on the cooling phenomenon of molten metal, simulated annealing (SA), is one of the most popular and effective evolutionary algorithms for searching the global optimum. SA gives a better performance than classical optimization methods, irrespective of the modality of the objective function [12], which is very much essential for a newly modeled system. However, in real world problem, it is not sufficient to optimize a single objective function; rather, a number of objective functions with similar or conflicting nature are required to be optimized. So, multiobjective optimization (MOO) has become an important research area for scientists.

In contrast to single objective optimization, a solution to a multiobjective problem is more of a concept than a definition. 
In case of single objective problem, the global optimum is unique. For multiobjective cases in many of the situations, there exist a number of solution sets of parameters, all of which equally satisfy the optimality criterion. In general, multiobjective optimization problem can be stated as follows [13]:

$$
\begin{array}{ll}
\text { minimize: } & F(x)=\left[F_{1}(x), F_{2}(x), \ldots, F_{k}(x)\right]^{T} \\
\text { subject to: } & g_{j}(x) \leq 0, \quad j=1(1) m \\
& h_{l}(x)=0, \quad l=1(1) e .
\end{array}
$$

For any given multiobjective optimization problem, there may be an infinite number of Pareto optimal points constituting the Pareto optimal set. But the engineers are very much concerned with the extreme limit of the solution spectrum, called Pareto front. Practically, Pareto front suggests a guideline to engineers not to go beyond this limit.

By definition, Pareto solution set is the nondominated solutions among all optimum points. The predominant concept in defining an optimal point is that of Pareto optimality [13] which is defined as follows.

Definition 1 (Pareto optimal). A point, $x^{*} \in X$, is Pareto optimal if and only if there does not exist another point, $x \in X$, such that $F(x) \leq F\left(x^{*}\right)$ and $F_{i}(x)<F_{i}\left(x^{*}\right)$ for at least one function.

All Pareto optimal points lie on the boundary of the optimum criterion space [14]. Often, algorithms provide solutions that may not be Pareto optimal but may satisfy other criteria, making them significant for practical applications. For instance, weakly Pareto optimal is defined as follows.

Definition 2 (weakly Pareto optimal). A point, $x^{*} \in X$, is weakly Pareto optimal if and only if there does not exist another point, $x \in X$, such that $F(x)<F\left(x^{*}\right)$.

A point is weakly Pareto optimal if there is no other point that improves all of the objective functions simultaneously. In contrast, a point is Pareto optimal if there is no other point that improves at least one objective function without detriment to another function. Pareto optimal points are weakly Pareto optimal, but weakly Pareto optimal points are not Pareto optimal.

A Pareto set is developed using the concept of an archive, where the nondominated solutions seen so far are stored, and is constantly updated. If the new solution is not updating the set, then the nonarchive solution is accepted according to the modified probability. It is different in various multiobjective simulated annealing search algorithms. In archived multiobjective simulated annealing (AMOSA) [15], a new state is selected with a probability

$$
P_{q s}=\frac{1}{\left(1+e^{-(E(q, T)-E(s, T)) / T}\right)},
$$

where $q$ is the current energy state and $E(s, T)$ and $E(q, T)$ are the corresponding energy values at states $s$ and $q$. In SMOSA $[16,17]$, a new acceptance probability formulation based on an annealing schedule with multiple temperatures (one for each objective) is also proposed. The key probability step is given as follows:

$$
P=\min \left(1, \prod e^{-\Delta s_{i} / T_{i}}\right)
$$

where $\Delta s_{i}=\left(z_{i}(Y)-z_{i}(X)\right), X$ is the current solution, $Y$ is the generated solution, $z_{i}$ is the objective function, and $T_{i}$ is the annealing temperature. Pareto simulated annealing (PSA) $[16,18]$ suggests the acceptance of a new solution with the following probability:

$$
P=\min \left(1, \prod e^{-\Delta s_{i} / T_{i}}\right),
$$

where $\Delta s_{i}=\lambda_{i}\left(z_{i}(Y)-z_{i}(X)\right)$. Here, all objectives are aggregated with a weighted sum of the objectives.

Adaptive simulated annealing [19] suggested that if some local minima are encountered at a relatively low temperature towards the end of search, traditional SA may not lead to a near optimal solution. To avoid this uncertainty, an adaptive cooling schedule was prescribed that adjusts the temperature dynamically based on the profile of the search path (including the possibility of reheating) instead of using traditional monotonically nonincreasing cooling schedule. In this method, the following temperature control function is used:

$$
\theta_{i}=\theta_{\min }+\lambda \ln \left(1+r_{i}\right),
$$

where $\theta_{\min }$ is the minimum value that the temperature can take, $\lambda$ is a coefficient that controls the rate of temperature rise, and $r_{i}$ is the number of consecutive upward moves at iteration $i$. The initial value of $r_{i}$ is zero; thus the initial temperature $\theta_{0}=\theta_{\text {min }}$.

In this present study, the proposed algorithm differs effectively in the concept of archiving the optimal solutions. The fundamental steps involved in the algorithm are as follows.

Step 1. Choose a large starting temperature $\left(t_{\max }\right)$ for annealing, temperature reduction parameter $\left(r_{c}\right)$, number of iteration at a particular temperature $(n)$ (both of these control the cooling schedule), and accuracy level. Select midpoints of the range of each variable as initial solution vector (current solution vector).

Step 2. Select weight factor (say $w_{1}$ and $w_{2}$ ) for each of the objective functions satisfying always the condition $w_{1}+w_{2}=$ 1 and convert the objective functions into a single one by using the following relationship:

converted objective function $=_{(i=1,2)} \sum$ (ith weight factor) $X$ (ith objective function at current solution vector).

Step 3. Give a random perturbation in the neighborhood of current solution vector, following the Gaussian distribution and setting the $6 \sigma$ limit as the range of parameters, to get a new solution.

Step 4. Calculate the converted objective function values at both new and current solution vectors. Also, find the change in function value, $\Delta E$. 
Step 5. Check the acceptance of the new solution vector for converted objective function using Boltzmann probability distribution and random number generation:

$$
\begin{aligned}
P & =1 \quad \text { if } \Delta E \leq 0 \\
& =e^{-\Delta E / T} \quad \text { if } \Delta E \geq 0 .
\end{aligned}
$$

Step 6. If the new solution is accepted, go to Step 7; otherwise, go to Step 3.

Step 7. If number of iteration (random perturbation) at this temperature is reached at the predefined limit $(n)$, go to Step 8; or else, set the new solution vector to current solution vector for next iteration at the same temperature and go to Step 3.

Step 8. Calculate the change in converted objective function value at the new solution point over the previous one.

Step 9. If the change in function value satisfies the accuracy level, then go to Step 10; otherwise, reduce the temperature using reducing parameter $\left(r_{c}\right)$ and set the new solution vector to current solution vector and go to Step 3.

Step 10. This new solution vector is stored in the optimum solution set. Then, choose a different weight factor combination vector and restart the whole simulation for obtaining another optimum solution. This iteration will take place according to the number of choices of weight factor combinations.

Finally, an archive of optimum solution will be obtained. Each point of this archive satisfies the optimum criteria. Here, two extreme converted objective functions are basically either of the two objective functions. Starting from one of the pure objective functions, the shape of converted objective function is gradually changed to another pure objective function.

Then, the Pareto solution sets are marked from this archive which indicates the extreme boundary of the optimum region. An approximate fitting is done through the Pareto solution vector to get a Pareto front. From this Pareto front, process engineers can easily determine and select the near-optimum operating conditions of the response parameters.

\section{Experiment}

The equipment used for the experiment is an EDM machine (Tool Craft A25 EDM machine). The machine operates with commercially available kerosene oil as dielectric medium and an open circuit voltage of 70 volts. High speed steel of specimen $\mathrm{C}-0.80 \%, \mathrm{~W}-6 \%, \mathrm{Mo}-5 \%, \mathrm{Cr}-4 \%, \mathrm{~V}-2 \%$ equivalent to grade M2 was chosen as the workpiece material. The density of material is $8144 \mathrm{~kg} / \mathrm{m}^{3}$. The tool material selected is electrolytic copper with density $8904 \mathrm{~kg} / \mathrm{m}^{3}$ and has circular cross section of $14 \mathrm{~mm}^{2}$. The polarity of the tool electrode is set as positive, while that of workpiece as negative. Current setting (cur), pulse on time $\left(t_{\text {on }}\right)$, and pulse off time $\left(t_{\text {off }}\right)$ are considered as input parameters and material
TABLE 1: Parameters and their levels.

\begin{tabular}{lcccc}
\hline & Level 1 & Level 2 & Level 3 & Level 4 \\
\hline Current setting $(\mathrm{A})$ & 3 & 6 & 9 & 12 \\
Pulse on time $(\mu \mathrm{s})$ & 50 & 100 & 150 & 200 \\
Pulse off time $(\mu \mathrm{s})$ & 50 & 100 & 150 & 200 \\
\hline
\end{tabular}

removal rate (MRR) and surface roughness $(\mathrm{Ra})$ of machined surface of workpiece are taken as response parameters. Based on the availability of the machine setting, levels of the control parameters are selected and presented in Table 1.

Experiment is carried out with 60 unique combinations of levels of the three different parameters. Material removal rate and average value of surface roughness are measured in each experimental run. For the purpose of determining the material removal rate (MRR), the loss in weight is measured by standard measuring balance. It is then divided by the density of workpiece material in order to convert it into volumetric term and is further divided by the actual machining time to obtain the MRR in terms of $\mathrm{mm}^{3} / \mathrm{min}$. The average surface roughness $(\mathrm{Ra})$ of the machined workpiece is then evaluated by the Taylor Hobson Precision Surtronics $3^{+}$ roughness checker. Here, a sample length of $4 \mathrm{~mm}$ is taken and stylus tip radius of $5 \mu \mathrm{m}$ is used. The value of surface roughness parameter $\mathrm{Ra}$ in micron for each experiment was obtained directly from the Talyprofile software integrated with machine. The arithmetic mean of the values of the measurements taken along three mutual $120^{\circ}$ directions over the area subjected to the EDM process is taken as the representative value of $\mathrm{Ra}$. The values of responses thus obtained are then considered for model building and optimization.

\section{Analysis and Discussion}

For the purpose of analysis, initially statistical models of MRR and $\mathrm{Ra}$ as a function of control parameters are developed from the experimental data. They are then considered as the pure objective functions in order to obtain the optimal working conditions in EDM process.

4.1. Model Development. Power law based models are simple to understand and include the higher order modeling in itself (as the power of the variable parameters is not predefined, but rather estimated from the experimental results). Logarithmic transformation of power law model to linear model renders simplification in mathematical treatment, both in forward and reverse directions. Power law functions are, therefore, assumed for model development and can be presented in the following form:

$$
\begin{gathered}
\text { MRR }=a_{0} \operatorname{cur}^{a_{1}} t_{\text {on }}^{a_{2}} t_{\text {off }}^{a_{3}} \\
\mathrm{Ra}=b_{0} \operatorname{cur}^{b_{1}} t_{\text {on }}^{b_{2}} t_{\text {off }}^{b_{3}} .
\end{gathered}
$$

Here, cur, $t_{\text {on }}$, and $t_{\text {off }}$ indicate current setting, pulse on time, and pulse off time, respectively, while $a_{i}$ and $b_{i}$ are constants of the corresponding power functions. They are 
then linearized by taking natural logarithmic values and the equations become

$$
\begin{gathered}
\ln (\mathrm{MRR})=\ln \left(a_{0}\right)+a_{1} \ln (\mathrm{cur})+a_{2} \ln \left(t_{\mathrm{on}}\right)+a_{3} \ln \left(t_{\mathrm{off}}\right), \\
\ln (\mathrm{Ra})=\ln \left(b_{0}\right)+b_{1} \ln (\mathrm{cur})+b_{2} \ln \left(t_{\mathrm{on}}\right)+b_{3} \ln \left(t_{\mathrm{off}}\right) .
\end{gathered}
$$

Based on the above linear models, simple regression analysis is performed with 60 experimental data in the MATLAB environment and unknown coefficients are found out. The expressions thus developed are given below:

$$
\begin{aligned}
\ln (\mathrm{MRR})= & -2.382413+2.135817 \ln (\text { cur }) \\
& +0.248408+\ln \left(t_{\text {on }}\right)-0.334234 \ln \left(t_{\text {off }}\right), \\
\ln (\mathrm{Ra})= & -0.321897+0.775938 \ln (\text { cur })+0.050886 \\
& +\ln \left(t_{\text {on }}\right)+0.035708 \ln \left(t_{\text {off }}\right) .
\end{aligned}
$$

Correlation coefficients are calculated and analysis of variance (ANOVA) is performed. High value of correlation coefficient (MRR: $r^{2}=0.9397$ and Ra: $r^{2}=0.9059$ ) of each of the fitted models indicates its adequacy. The ANOVA depicts the contributive effect of the factors and their interactions with material removal rate and average surface roughness, respectively (Tables 2 and 3 ).

The linear relationships are then returned back to the power law functions, that is, in exponential form:

$$
\begin{aligned}
\text { MRR } & =e^{-2.382413} \operatorname{cur}^{2.135817} t_{\text {on }}^{0.248408} t_{\text {off }}^{-0.334234} \\
\mathrm{Ra} & =e^{-0.321897} \mathrm{cur}^{0.775938} t_{\text {on }}^{0.050886} t_{\text {off }}^{0.035708} .
\end{aligned}
$$

To depict the different factor effects, the surface plots are generated. The representative surface plots are shown in Figures 1, 2, 3, 4, 5, and 6. Current, pulse on time, and their interaction are observed as the common significant contributive factors to both the material removal rate and average surface roughness.

4.2. Weight-Varying Multiobjective Simulated Annealing. Higher MRR indicates high productivity, while lower Ra provides better surface finish. So, for better machining performance, MRR should be maximized and Ra should be minimized simultaneously. For optimization, two objective functions are set as follows:

$$
\begin{gathered}
f\left(\text { cur }, t_{\text {on }}, t_{\text {off }}\right)=\text { MRR, } \\
h\left(\text { cur, } t_{\text {on }}, t_{\text {off }}\right)=\mathrm{Ra},
\end{gathered}
$$

where $f$ and $h$ are to be maximized and minimized, respectively. Generally, simulated annealing is used for minimization problem. So, for this purpose, maximization problem is converted to minimization problem by just taking the reciprocal:

$$
\begin{aligned}
& f_{1}=\frac{1}{M R R}, \\
& f_{2}=\text { Ra. }
\end{aligned}
$$

According to the newly proposed simulated annealing based weight-varying multiobjective optimization technique, at first pure objective functions are converted to a single objective function in the following way:

converted objective function: $f=w_{1}\left(\frac{1}{\mathrm{MRR}}\right)+w_{2}(\mathrm{Ra})$.

Here, $w_{1}$ and $w_{2}$ are the weight factors satisfying the relation $w_{1}+w_{2}=1$. Value of this function is effectively controlled by the value of each objective function. As a result, both of these functions will not be fairly weighted. To avoid this problem, normalization of the function is done by dividing each of the function values by its maximum value:

normalized converted objective function:

$$
f^{*}=w_{1} \frac{1 / \mathrm{MRR}}{(1 / \mathrm{MRR})_{\max }}+w_{2} \frac{\mathrm{Ra}}{\mathrm{Ra}_{\max }} .
$$

Two extreme cases of this normalized converted objective function $\left(f^{*}\right)$ are either $f_{1}^{*}$ or $f_{2}^{*}$. The change in the shape of $f^{*}$ with the most effective control parameter, current, is shown in Figure 7.

Here, input factors for optimization are set as follows. Annealing begins from $\left(t_{\max }\right) 250^{\circ} \mathrm{C}$ and cooling schedule is controlled by temperature reduction parameter $\left(r_{c}\right) 0.975$ and number of iteration at a particular temperature $(n) 100$. Termination criterion is set by accuracy level, 0.001 . Also, $(1 / \mathrm{MRR})_{\max }$ and $\mathrm{Ra}_{\max }$ are set as 3.0 and 10.0, respectively, as found from experimental data.

Generally, in case of multiobjective optimization, different optimum points would be obtained if started from different initial solution vectors. But, for the weight-varying multiobjective simulated annealing, initial solution vector may be fixed at a position of user's choice. In the present problem, midpoint of the search space, that is, current setting $=7.5 \mathrm{~A}$, pulse on time $=125 \mu \mathrm{s}$, and pulse off time $=125 \mu \mathrm{s}$ is chosen for the purpose. Now, the weight factors are being changed from zero to unity in steps of 0.001 . So, 1001 combinations of weight factors are obtained. Each combination changes the shape of normalized converted objective function. Different shapes of objective functions give different optimal responses (a set of MRR and Ra) and corresponding control parameter settings. Flow chart for optimization by above proposed weight-varying multiobjective simulated annealing method is shown in Figure 8.

Optimizing the normalized converted objective function $\left(f^{*}\right)$ by weight-varying multiobjective simulated annealing, a set of 1001 optimal points is obtained (Figure 9). Ranges of optimum values of MRR and Ra are $0.5663 \mathrm{~mm}^{3} / \mathrm{min}$ to $16.5910 \mathrm{~mm}^{3} / \mathrm{min}$ and $2.5623 \mu \mathrm{m}$ to $7.7542 \mu \mathrm{m}$, respectively. Each point of these spectra provides optimum performance. From these sets, an extreme limit, called Pareto front (the lowest boundary of Ra versus MRR plotting gives the Pareto front), is determined in the following way, assuming the front as a continuous function.

Pareto optimal data are first identified (Table 4). The data are then fitted in a 4th order polynomial equation using 


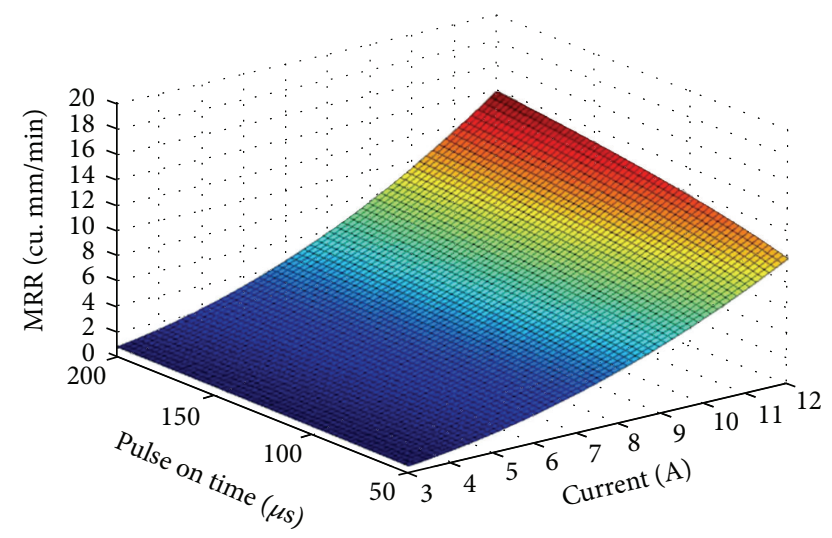

FIGURE 1: Effect of current and pulse on time on material removal rate $(\mathrm{MRR})$ at pulse off time $=125 \mu \mathrm{s}$.

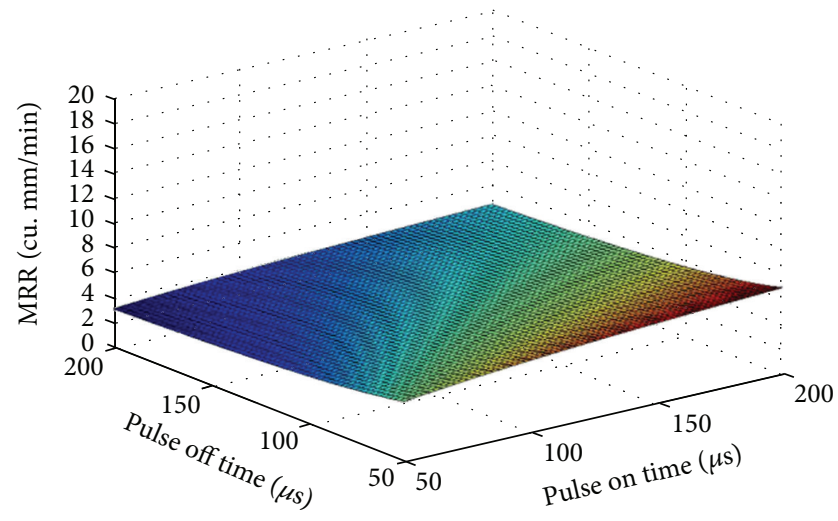

FIGURE 2: Effect of pulse on time and pulse off time on material removal rate $(\mathrm{MRR})$ at current $=7.5 \mathrm{~A}$.

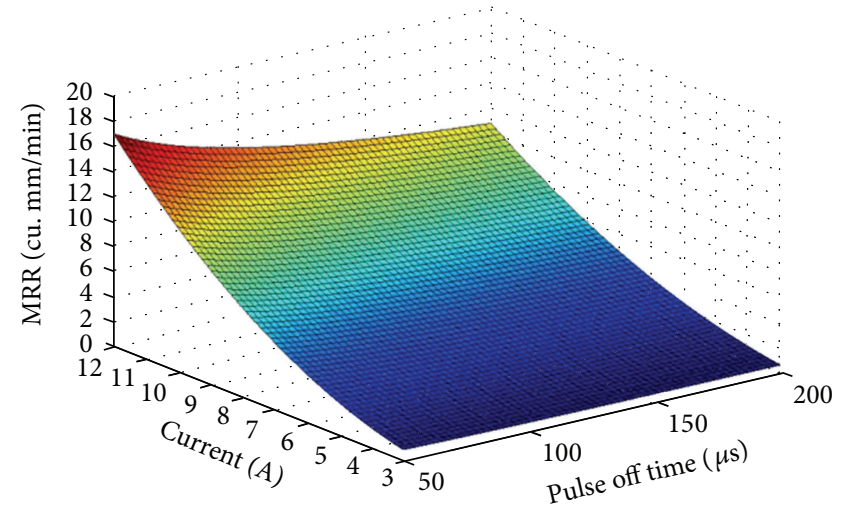

FIGURE 3: Effect of pulse off time and current on material removal rate $(\mathrm{MRR})$ at pulse on time $=125 \mu \mathrm{s}$.

MATLAB R2012a environment. Equation (15) thus generated with estimated correlation coefficient $r^{2}=0.9997$ presents the Pareto front for the present problem shown by solid line in Figure 9:

$$
\begin{aligned}
\mathrm{Ra}= & -0.000167(\mathrm{MRR})^{4}+0.006818(\mathrm{MRR})^{3} \\
& -0.106529(\mathrm{MRR})^{2}+0.977000(\mathrm{MRR})+1.802258 .
\end{aligned}
$$

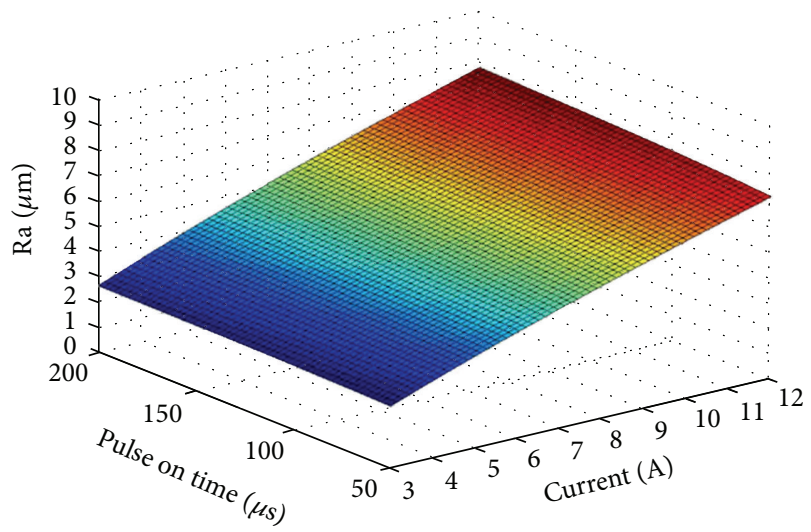

FIGURE 4: Effect of current and pulse on time on surface roughness (Ra) at pulse off time $=125 \mu \mathrm{s}$.

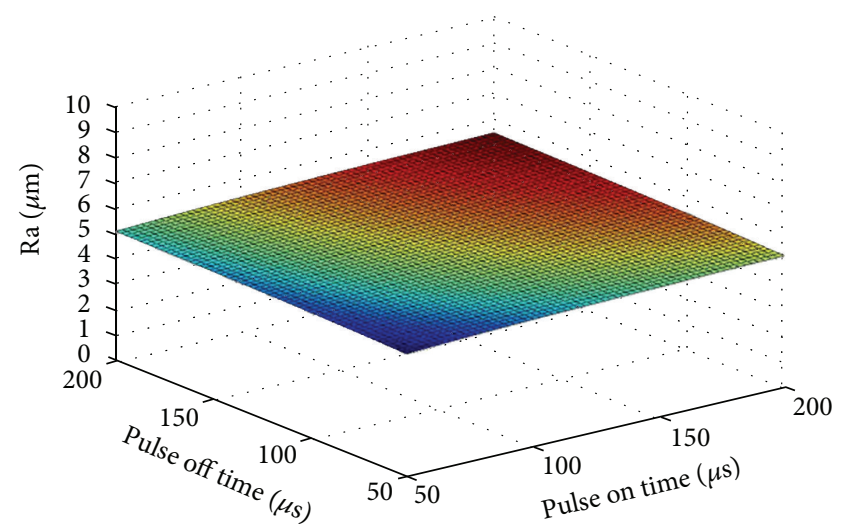

FIGURE 5: Effect of pulse on time and pulse off time on surface roughness $(\mathrm{Ra})$ at current $=7.5 \mathrm{~A}$.

The Pareto front equation (see (15)) representing Ra as a polynomial function of MRR is validated through experimental observations. Validation results are listed in Table 5. Percentage deviation of estimated surface roughness (using (15)) values from corresponding experimental results lies in between $-9.5684 \%$ and $+8.5938 \%$. The significance of the front is that all optimum points should lie behind it; that is, no other optimum setting would cross this limit. This line shows that as MRR increases, the extreme boundary of possible near-optimum $\mathrm{Ra}$ also increases.

4.2.1. Validation. In real world practice, control parameter settings to obtain optimum responses are very much essential for better machining performance. Though Pareto optimal data set gives a list of such settings, practically it is reasonably difficult to set these values in EDM machine. That is why an inverse solution procedure is devised for getting reasonably close settings of control parameters according to their availability in the machine. To the best of authors' knowledge, still no such work is reported in literature regarding the optimum control parameter settings to obtain a specific MRR and Ra combination.

From Pareto front equation (15), Ra value can be easily predicted for a particular MRR value. To get a particular 


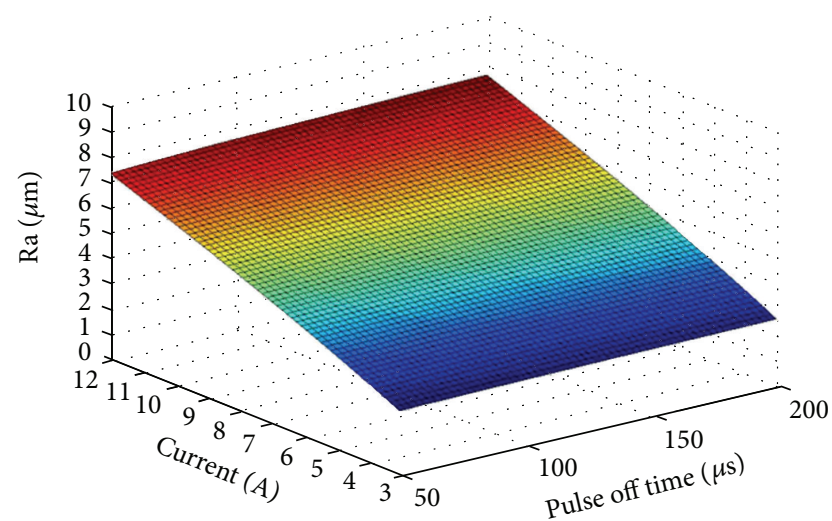

FIGURE 6: Effect of pulse off time and current on surface roughness (Ra) at pulse on time $=125 \mu \mathrm{s}$.

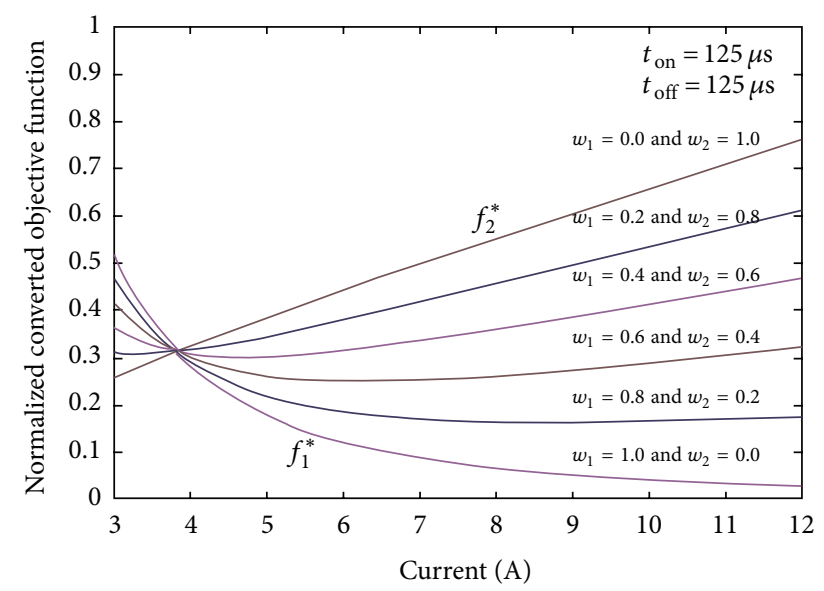

FIGURE 7: Shape change of normalized converted objective function for different weight factor combination.

MRR, different combinations of current, pulse on time, and pulse off time are possible. This line would guide to select a specific combination among these which gives lowest $\mathrm{Ra}$ simultaneously. Still, confusion remains regarding the settings of control parameters in the machine to obtain that particular MRR and Ra combination. The following method will give a way to arrive at control parameter settings.

First, this set of MRR and Ra values is substituted in (10). These equations are turned to be a set of 2 equations with 3 unknowns (nothing but control parameters). Mathematically, this gives infinite number of solutions. Hence, pulse off time is chosen as fixed parameter having four $(50 \mu \mathrm{s}, 100 \mu \mathrm{s}, 150 \mu \mathrm{s}$, and $200 \mu \mathrm{s}$ ) different values. This is justified as this parameter does not have any significant effect on Ra. The equations are then solved to obtain a set of current setting and pulse on time for a fixed pulse off time. Thus, to get a particular MRR and Ra combination, four combinations of control parameter settings are available. All of these settings may or may not be within the experimental range. The out of range data are just omitted.

In the present study, for the sake of simplicity, experimental data are used for the purpose of validation. All experimental MRR values are put in (15) and a set of corresponding optimum Ra values are obtained. Following the above stated steps of solving (10), a set of current, pulse on time, and pulse off time corresponding to each combination of MRR and $\mathrm{Ra}$ is obtained.

A comparison is done among the calculated control parameter settings and nearest experimental settings. Considering maximum 20\% deviation between optimum and experimental values, a list is thus prepared (shown in Table 6). It is easily observed that the experimental results approach closely the optimum values.

4.3. Discussion. As electrical discharge machining is a thermoelectric material removal process, so each of the thermal and electrical attributes substantially influences the process. Thus, values of responses like $\mathrm{MRR}$ and $\mathrm{Ra}$ are found differently in different ranges of parameter settings including electrode materials. To the best of the authors' knowledge, still no unique procedure exists that could direct a process engineer for selecting optimum parameter settings for a need based requirement of responses.

In the present work, therefore, a simple procedure is adopted for effective modeling of two conflicting responses, MRR and Ra in EDM, and an easy to operate weight-varying simulated annealing procedure is proposed for optimization with an aim to develop a Pareto optimal front.

In previous published papers on multiobjective optimization of EDM responses, researchers mostly implemented either simulated annealing [11] or NSGA-II [10]. Simulated annealing is applied to single objective function which is obtained as a weighted combination of multiple objectives [11]. So, for a particular combination of MRR and Ra, SA gives a specific optimum setting, even if started from different location in the search space. The best value of parameter settings thus obtained for a fixed value (not reported) of associated weights was voltage $127.88 \mathrm{~V}$, current $33.90 \mathrm{~A}$, on time $412.22 \mu \mathrm{s}$, and off time $109.58 \mu \mathrm{s}$ [11] (not achievable without stepless variation of machine settings). This would not provide any idea of exhaustive possible optimum settings of machine parameters which will satisfy both the responses simultaneously. Once the multiple objectives are combined to a single one, the essence of simultaneous optimization may be pale. If the weighted combinations are varied between two extreme cases, that is, two pure single objectives assigned with 1.0 weight factor to either of them, different possibilities of their contributive effect may be studied. Another wellknown multiobjective optimization technique is NSGA-II. All points of the initial population are directed to the optimum points; that is, a set of equally probable optimum points can be obtained. [10]. Optimum results, whatever were found, may be changed with different initial population, with different combination of selection pressure and population diversity, with different strategy of mutation, and with different combination of GA parameters for multiobjective optimization. The procedure depends largely on heuristics and is computationally complex.

Thus, a simple procedure is forwarded in the present study. Though MRR and Ra are combined with weight factors, simulation is carried out with different 1001 sets of weight factor combinations. Actually, the objective function 


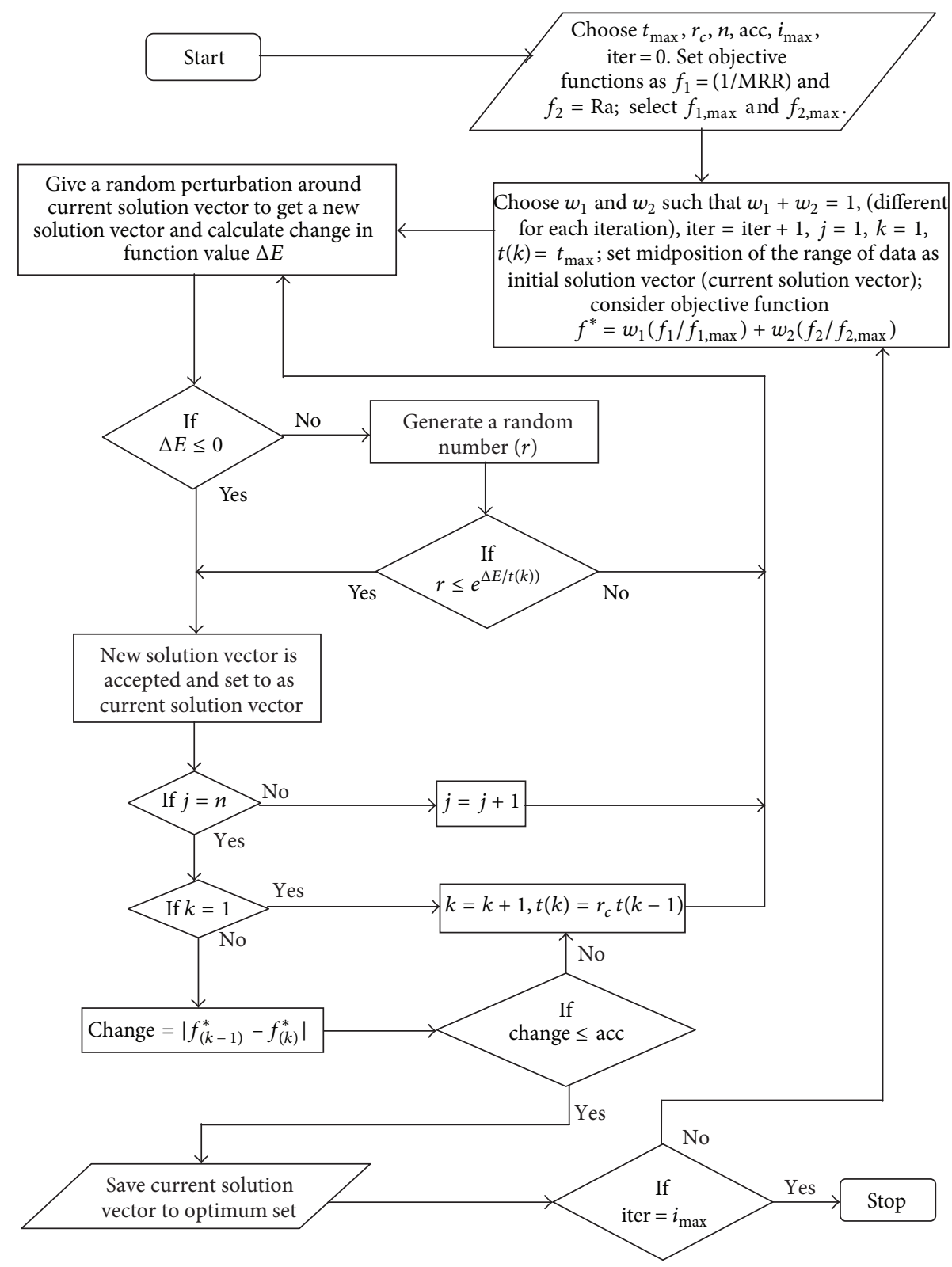

FIGURE 8: Flow chart for weight-varying multiobjective simulated annealing.

TABLE 2: ANOVA for MRR

\begin{tabular}{lcccccc}
\hline Control factors & Degrees of freedom & Sum of squares & Mean square & $F$ value & $P$ value & \% contribution \\
\hline Current & 3 & 69.2335 & 23.0778 & 979.87 & 0 & 85.1978 \\
Pulse on time & 3 & 1.3227 & 0.4409 & 18.72 & 0 & 1.6277 \\
Pulse off time & 3 & 2.4216 & 0.8072 & 34.27 & 0 & 2.9800 \\
Current $*$ pulse on time & 9 & 0.7013 & 0.0779 & 3.31 & 0.0098 & 0.8630 \\
Current $*$ pulse off time & 9 & 0.6058 & 0.0673 & 2.86 & 0.0203 & 0.7455 \\
Pulse on time $*$ pulse off time & 9 & 0.4232 & 0.0470 & 2.00 & 0.0874 \\
Error & 23 & 0.5417 & 0.0236 & & & 0.5208 \\
Total & 59 & 81.2621 & & & \\
\hline
\end{tabular}


TABLE 3: ANOVA for Ra.

\begin{tabular}{lcccccc}
\hline Control factors & Degrees of freedom & Sum of squares & Mean square & $F$ value & $P$ value & \% contribution \\
\hline Current & 3 & 9.2521 & 3.08403 & 572.93 & 0 & 87.1713 \\
Pulse on time & 3 & 0.0468 & 0.01560 & 2.90 & 0.0568 & 0.4409 \\
Pulse off time & 3 & 0.0251 & 0.00836 & 1.55 & 0.2279 & 0.2365 \\
Current $*$ pulse on time & 9 & 0.3186 & 0.03540 & 6.58 & 0.0001 & 3.0018 \\
Current $*$ pulse off time & 9 & 0.0509 & 0.00565 & 1.05 & 0.4331 & 0.4796 \\
Pulse on time $*$ pulse off time & 9 & 0.0439 & 0.00487 & 0.91 & 0.5369 & 0.4136 \\
Error & 23 & 0.1238 & 0.00538 & & & \\
Total & 59 & 10.6137 & & & &
\end{tabular}

Table 4: Pareto optimal data.

\begin{tabular}{lccccc}
\hline Sl. number & Current $(\mathrm{A})$ & Pulse on time $(\mu \mathrm{s})$ & Pulse off time $(\mu \mathrm{s})$ & MRR $\left(\mathrm{mm}^{3} / \mathrm{min}\right)$ & Surface roughness Ra $(\mu \mathrm{m})$ \\
\hline 1 & 3.2505 & 112.2513 & 51.1226 & 0.9931 & 2.6472 \\
2 & 3.2007 & 186.2101 & 62.8999 & 1.0167 & 2.7039 \\
3 & 3.5159 & 152.0621 & 59.5258 & 2.0442 & 2.8727 \\
4 & 4.3200 & 184.0898 & 52.4232 & 3.0607 & 3.3881 \\
5 & 5.3498 & 142.3933 & 50.7613 & 4.0139 & 3.9430 \\
6 & 6.1709 & 149.2655 & 58.1771 & 4.4528 & 4.4372 \\
7 & 6.4110 & 160.3530 & 57.4053 & 4.5398 & 4.5850 \\
8 & 6.4784 & 148.9181 & 54.8232 & 5.1999 & 4.5975 \\
9 & 6.9351 & 143.8910 & 55.0203 & 6.2705 & 4.8392 \\
10 & 7.6679 & 120.8713 & 52.4492 & 7.1365 & 5.1764 \\
11 & 7.9184 & 167.9898 & 55.8643 & 7.2498 & 5.4089 \\
12 & 7.9896 & 166.5864 & 56.0781 & 7.7870 & 5.4450 \\
13 & 8.2197 & 153.3664 & 51.0527 & 7.9579 & 5.5244 \\
14 & 8.2791 & 163.1149 & 52.4431 & 10.1120 & 5.5782 \\
15 & 9.3241 & 161.3686 & 54.3023 & 11.2680 & 6.1214 \\
16 & 9.7196 & 167.6475 & 52.6972 & 14.5464 & 6.3275 \\
17 & 11.0491 & 173.2534 & 57.0642 & 15.5237 & 7.0209 \\
18 & 11.2095 & 185.5017 & 54.1914 & & 7115 \\
\hline
\end{tabular}

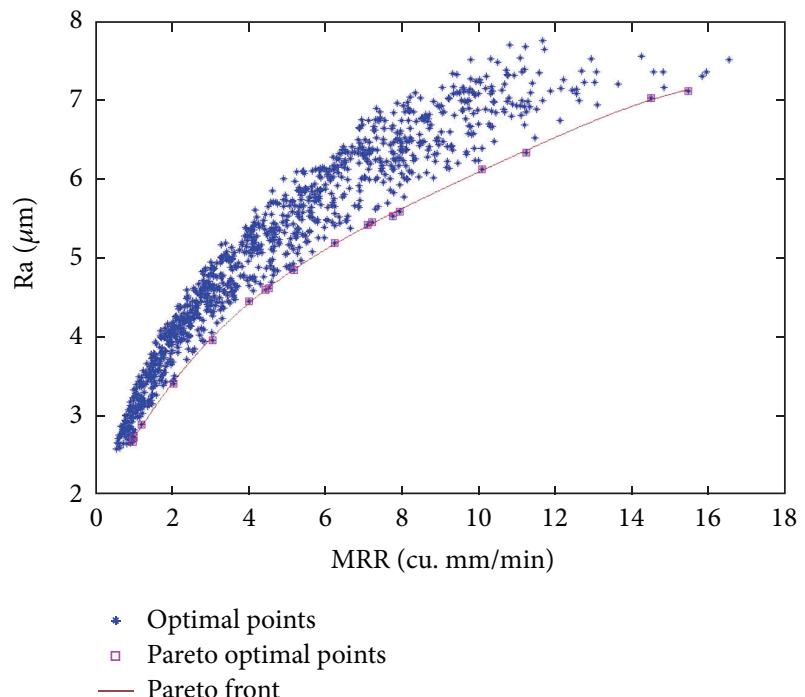

FIGURE 9: Optimal solution set for weighted objective functions and Pareto front $(n=100$, accuracy $=0.001)$. is gradually varied from one objective to another one. This includes almost all possible practical combinations of these two responses. In each of these, a single optimum result is found and finally the spectrum of all possible optimum points gives an idea of exhaustive optimum zone of responses (Figure 9). So, the extreme boundary of this zone could ensure that no other optimum lies below it. This boundary line is identified as the Pareto optimal front. This is an easy way to mark the Pareto front for multiple objectives.

Further, in all previously published papers, optimum points are reported, but to set these values in machine is very difficult unless any stepless variation with higher precision is available. Here, a simple way to solve this problem is suggested. Also, the Pareto front (assuming it to be a continuous one) equation shows a guideline to meet user specific demand of MRR or Ra. For a particular MRR or Ra, number of machine parameter combinations is possible, but to identify that specific combination which would give minimum Ra or maximum MRR simultaneously with the user specified demand is very difficult. This front line would give achievable 
TABle 5: Validation of Pareto front equation.

\begin{tabular}{|c|c|c|c|c|}
\hline Sl. number & $\operatorname{MRR}\left(\mathrm{mm}^{3} / \mathrm{min}\right)$ & $\begin{array}{c}\mathrm{Ra}(\mu \mathrm{m}) \\
\text { (estimated) }\end{array}$ & $\begin{array}{c}\mathrm{Ra}(\mu \mathrm{m}) \\
\text { (experimental) }\end{array}$ & $\%$ deviation \\
\hline 1 & 5.7718 & 5.0192 & 5.02 & 0.0165 \\
\hline 2 & 0.6497 & 2.3939 & 2.41 & 0.6685 \\
\hline 3 & 0.7899 & 2.5108 & 2.48 & 1.2427 \\
\hline 4 & 0.9071 & 2.6058 & 2.57 & 1.3936 \\
\hline 5 & 0.7061 & 2.4414 & 2.48 & 1.5579 \\
\hline 6 & 8.2535 & 5.6721 & 5.77 & 1.6962 \\
\hline 7 & 6.5304 & 5.2363 & 5.34 & 1.9421 \\
\hline 8 & 12.6351 & 6.6619 & 6.51 & 2.3334 \\
\hline 9 & 10.1742 & 6.1170 & 6.29 & 2.7504 \\
\hline 10 & 0.7731 & 2.4970 & 2.57 & 2.8406 \\
\hline 11 & 4.1619 & 4.4649 & 4.33 & 3.1156 \\
\hline 12 & 11.4031 & 6.3937 & 6.65 & 3.8536 \\
\hline 13 & 18.8113 & 7.0825 & 7.45 & 4.9324 \\
\hline 14 & 3.7873 & 4.1307 & 4.54 & 5.0515 \\
\hline 15 & 0.6134 & 2.3630 & 2.24 & 5.4918 \\
\hline 16 & 0.6099 & 2.3600 & 2.22 & 6.3076 \\
\hline 17 & 14.1423 & 6.9576 & 6.53 & 6.5478 \\
\hline 18 & 12.3972 & 6.6113 & 7.18 & 7.7902 \\
\hline 19 & 0.5608 & 2.3178 & 2.15 & 7.8066 \\
\hline 20 & 0.3427 & 2.1248 & 2.31 & 8.0157 \\
\hline 21 & 8.1302 & 5.6426 & 6.15 & 8.2499 \\
\hline 22 & 15.3902 & 7.1469 & 7.79 & 8.2550 \\
\hline 23 & 4.886 & 4.7334 & 4.36 & 8.5638 \\
\hline 24 & 3.7811 & 4.3080 & 4.77 & 9.0853 \\
\hline 25 & 0.3924 & 2.1696 & 2.40 & 9.5984 \\
\hline
\end{tabular}

near-optimum value of other responses when one is made fixed. It would be then easier to find the machine parameter setting using the backpropagation technique discussed in Section 4.2.1. Thus, it is possible to find process parameter setting among the available settings of the parameters in the machine, which would give near optimum of the other response simultaneously for any need based requirement of one response. Here lies the novelty of this study.

\section{Conclusion}

As technology advances, stochastic type EDM process becomes more popular for precision engineering and optimum machining performance becomes important to the manufacturer. In the present paper, an easy to handle procedure for engineers, weight-varying multiobjective simulated annealing, is proposed to find the optimal settings of process parameters that will optimize simultaneously two conflicting type responses, MRR and Ra, in EDM. A Pareto front is estimated which will guide the process engineers regarding the extreme boundary of optimum responses and suggest the possible near-optimum combination of MRR and $\mathrm{Ra}$. The proposed inverse solution procedure for validation will effectively help the engineers to estimate and set the control parameters to get specific near-optimum MRR-Ra combination in real world practice. Thus, operator can easily predict and select the input factors' value according to output requirement.

\section{Nomenclature}

$\begin{array}{ll}a_{i}, b_{i}: & \text { Coefficients of power law models } \\ \text { cur: } & \text { Current setting (A) } \\ E(q, T), E(s, T): & \text { Energy value at states } q \text { and } s \\ e: & \text { Number of equality constraints } \\ F(x): & \text { Vector of objective functions (points in } \\ & \text { the criteria space) } \\ f^{*}: & \text { Normalized converted objective } \\ f_{1}, f_{2}, Z_{i}: & \text { function } \\ k: & \text { Objective function } \\ \text { MRR: } & \text { Number of objective functions } \\ m: & \left.\text { Material removal rate (mm }{ }^{3} / \mathrm{min}\right) \\ P: & \text { Number of inequality constraints } \\ \text { Ra: } & \text { Probability } \\ r_{i}: & \text { Average surface roughness }(\mu \mathrm{m}) \\ T: & \text { Consecutive upward move in } i \text { th } \\ & \text { iteration }\end{array}$


TABLE 6: Validation.

\begin{tabular}{|c|c|c|c|c|c|c|}
\hline Sl. number & & Current (A) & Pulse on time $(\mu \mathrm{s})$ & Pulse off time $(\mu \mathrm{s})$ & $\operatorname{MRR}\left(\mathrm{mm}^{3} / \mathrm{min}\right)$ & Surface roughness $\mathrm{Ra}(\mu \mathrm{m})$ \\
\hline \multirow{3}{*}{1} & Optimum & 11.7129 & 108.3082 & 50.0000 & 15.3242 & 7.1387 \\
\hline & Experimental & 12.0000 & 100.0000 & 50.0000 & 14.1423 & 6.5300 \\
\hline & $\%$ deviation & 2.4511 & 7.6709 & 0.0000 & 7.7126 & 8.5268 \\
\hline \multirow{3}{*}{2} & Optimum & 11.7221 & 109.4571 & 50.0000 & 15.3902 & 7.1469 \\
\hline & Experimental & 12.0000 & 100.0000 & 50.0000 & 14.1423 & 6.5300 \\
\hline & $\%$ deviation & 2.3707 & 8.6400 & 0.0000 & 8.1084 & 8.6317 \\
\hline \multirow{3}{*}{3} & Optimum & 10.1138 & 116.4332 & 50.0000 & 11.4031 & 6.3937 \\
\hline & Experimental & 9.0000 & 100.0000 & 50.0000 & 11.4031 & 6.6500 \\
\hline & $\%$ deviation & 11.0127 & 14.1138 & 0.0000 & 0.0000 & 4.0086 \\
\hline \multirow{3}{*}{4} & Optimum & 11.3966 & 99.2134 & 50.0000 & 14.1423 & 6.9576 \\
\hline & Experimental & 12.0000 & 100.0000 & 50.0000 & 14.1423 & 6.5300 \\
\hline & $\%$ deviation & 5.2946 & 0.7928 & 0.0000 & 0.0000 & 6.1458 \\
\hline \multirow{3}{*}{5} & Optimum & 7.0399 & 97.3798 & 50.0000 & 5.0313 & 4.7831 \\
\hline & Experimental & 6.0000 & 100.0000 & 50.0000 & 5.7718 & 5.0200 \\
\hline & $\%$ deviation & 14.7715 & 2.6907 & 0.0000 & 14.7179 & 4.9528 \\
\hline \multirow{3}{*}{6} & Optimum & 10.7318 & 105.6763 & 50.0000 & 12.6351 & 6.6619 \\
\hline & Experimental & 12.0000 & 100.0000 & 50.0000 & 14.1423 & 6.5300 \\
\hline & $\%$ deviation & 11.8172 & 5.3714 & 0.0000 & 11.9287 & 1.9799 \\
\hline \multirow{3}{*}{7} & Optimum & 10.2723 & 113.6373 & 50.0000 & 11.7172 & 6.4633 \\
\hline & Experimental & 9.0000 & 100.0000 & 50.0000 & 11.4031 & 6.6500 \\
\hline & $\%$ deviation & 12.3857 & 12.0007 & 0.0000 & 2.6807 & 2.8886 \\
\hline \multirow{3}{*}{8} & Optimum & 10.6142 & 107.6154 & 50.0000 & 12.3972 & 6.6113 \\
\hline & Experimental & 12.0000 & 100.0000 & 50.0000 & 14.1423 & 6.5300 \\
\hline & $\%$ deviation & 13.0561 & 7.0765 & 0.0000 & 14.0766 & 1.2297 \\
\hline \multirow{3}{*}{9} & Optimum & 11.4466 & 211.3767 & 50.0000 & 17.2259 & 7.2552 \\
\hline & Experimental & 12.0000 & 200.0000 & 50.0000 & 17.2259 & 8.3500 \\
\hline & $\%$ deviation & 4.8346 & 5.3822 & 0.0000 & 0.0000 & 15.0899 \\
\hline \multirow{3}{*}{10} & Optimum & 9.9756 & 118.7713 & 50.0000 & 11.1278 & 6.3323 \\
\hline & Experimental & 9.0000 & 100.0000 & 50.0000 & 11.4031 & 6.6500 \\
\hline & $\%$ deviation & 9.7799 & 15.8046 & 0.0000 & 2.4740 & 5.0171 \\
\hline \multirow{3}{*}{11} & Optimum & 9.0204 & 126.8568 & 50.0000 & 9.1232 & 5.8762 \\
\hline & Experimental & 9.0000 & 150.0000 & 50.0000 & 10.1742 & 6.2900 \\
\hline & $\%$ deviation & 0.2261 & 18.2456 & 0.0000 & 11.5201 & 7.0420 \\
\hline \multirow{3}{*}{12} & Optimum & 2.5232 & 195.9626 & 100.0000 & 0.5306 & 2.2917 \\
\hline & Experimental & 3.0000 & 200.0000 & 100.0000 & 0.5306 & 1.9200 \\
\hline & $\%$ deviation & 18.8966 & 2.0603 & 0.0000 & 0.0000 & 16.2194 \\
\hline \multirow{3}{*}{13} & Optimum & 7.4694 & 101.7217 & 50.0000 & 5.7718 & 5.0192 \\
\hline & Experimental & 6.0000 & 100.0000 & 50.0000 & 5.7718 & 5.0200 \\
\hline & $\%$ deviation & 19.6723 & 1.6926 & 0.0000 & 0.0000 & 0.0159 \\
\hline \multirow{3}{*}{14} & Optimum & 9.1521 & 127.0085 & 50.0000 & 9.4129 & 5.9430 \\
\hline & Experimental & 9.0000 & 150.0000 & 50.0000 & 10.1742 & 6.2900 \\
\hline & $\%$ deviation & 1.6619 & 18.1023 & 0.0000 & 8.0878 & 5.8388 \\
\hline \multirow{3}{*}{15} & Optimum & 7.1133 & 97.8662 & 50.0000 & 5.1503 & 4.8230 \\
\hline & Experimental & 6.0000 & 100.0000 & 50.0000 & 5.7718 & 5.0200 \\
\hline & \% deviation & 15.6551 & 2.1803 & 0.0000 & 12.0673 & 4.0846 \\
\hline \multirow{3}{*}{16} & Optimum & 9.8250 & 121.1347 & 50.0000 & 10.8249 & 6.2642 \\
\hline & Experimental & 9.0000 & 100.0000 & 50.0000 & 11.4031 & 6.6500 \\
\hline & $\%$ deviation & 8.3969 & 17.4473 & 0.0000 & 5.3414 & 6.1588 \\
\hline \multirow{3}{*}{17} & Optimum & 7.0629 & 97.5206 & 50.0000 & 5.0682 & 4.7956 \\
\hline & Experimental & 6.0000 & 100.0000 & 50.0000 & 5.7718 & 5.0200 \\
\hline & $\%$ deviation & 15.0491 & 2.5424 & 0.0000 & 13.8826 & 4.6793 \\
\hline
\end{tabular}


TABLE 6: Continued.

\begin{tabular}{ccccccc}
\hline Sl. number & & Current $(\mathrm{A})$ & Pulse on time $(\mu \mathrm{s})$ & Pulse off time $(\mu \mathrm{s})$ & $\mathrm{MRR}\left(\mathrm{mm}^{3} / \mathrm{min}\right)$ & Surface roughness Ra $(\mu \mathrm{m})$ \\
\hline \multirow{3}{*}{18} & Optimum & 2.5234 & 244.7705 & 100.0000 & 0.5608 & 2.3178 \\
& Experimental & 3.0000 & 200.0000 & 100.0000 & 0.5306 & 1.9200 \\
& \% deviation & 18.8872 & 18.2908 & 0.0000 & 5.3852 & 17.1628 \\
\hline \multirow{2}{*}{19} & Optimum & 7.0874 & 97.6826 & 50.0000 & 5.1080 & 4.8089 \\
& Experimental & 6.0000 & 100.0000 & 50.0000 & 5.7718 & 5.0200 \\
& \% deviation & 15.3427 & 2.3724 & 0.0000 & 12.9953 & 4.3898 \\
\multirow{2}{*}{20} & Optimum & 7.2141 & 98.7074 & 50.0000 & 5.3188 & 4.8781 \\
& Experimental & 6.000 & 100.0000 & 50.0000 & 5.7718 & 5.0200 \\
& \% deviation & 16.8295 & 1.3095 & 0.0000 & 8.5170 & 2.9089 \\
\hline
\end{tabular}

$t_{\text {off }}: \quad$ Pulse off time $(\mu \mathrm{s})$

$t_{\text {on }}: \quad$ Pulse on time $(\mu \mathrm{s})$

$w_{1}, w_{2}, \lambda$ : Weight factors

$X: \quad$ Feasible design space, current solution

$x$ : $\quad$ Vector of design variable (points in the design space)

$Y: \quad$ Generated solution

$\Delta E: \quad$ Change of energy value

$\Delta s_{i}: \quad$ Change in $i$ th objective function value.

\section{Conflict of Interests}

The authors declare that there is no conflict of interests regarding the publication of this paper.

\section{References}

[1] K. H. Ho and S. T. Newman, "State of the art electrical discharge machining (EDM)," International Journal of Machine Tools and Manufacture, vol. 43, no. 13, pp. 1287-1300, 2003.

[2] M. Kunieda, B. Lauwers, K. P. Rajurkar, and B. M. Schumacher, "Advancing EDM through fundamental insight into the process," CIRP Annals: Manufacturing Technology, vol. 54, no. 2, pp. 599-622, 2005.

[3] N. Mohd Abbas, D. G. Solomon, and M. Fuad Bahari, "A review on current research trends in electrical discharge machining (EDM)," International Journal of Machine Tools and Manufacture, vol. 47, no. 7-8, pp. 1214-1228, 2007.

[4] C. L. Lin, J. L. Lin, and T. C. Ko, "Optimisation of the EDM process based on the orthogonal array with fuzzy logic and grey relational analysis method," International Journal of Advanced Manufacturing Technology, vol. 19, no. 4, pp. 271-277, 2002.

[5] J. L. Lin and C. L. Lin, "The use of grey-fuzzy logic for the optimization of the manufacturing process," Journal of Materials Processing Technology, vol. 160, no. 1, pp. 9-14, 2005.

[6] Y. Tzeng and F. Chen, "Multi-objective optimisation of highspeed electrical discharge machining process using a Taguchi fuzzy-based approach," Materials and Design, vol. 28, no. 4, pp. 1159-1168, 2007.

[7] K. Wang, H. L. Gelgele, Y. Wang, Q. Yuan, and M. Fang, "A hybrid intelligent method for modelling the EDM process," International Journal of Machine Tools and Manufacture, vol. 43, no. 10, pp. 995-999, 2003.

[8] J. C. Su, J. Y. Kao, and Y. S. Tarng, "Optimisation of the electrical discharge machining process using a GA-based neural network," International Journal of Advanced Manufacturing Technology, vol. 24, no. 1-2, pp. 81-90, 2004.

[9] S. Kuriakose and M. S. Shunmugam, "Multi-objective optimization of wire-electro discharge machining process by nondominated sorting genetic algorithm," Journal of Materials Processing Technology, vol. 170, no. 1-2, pp. 133-141, 2005.

[10] D. Mandal, S. K. Pal, and P. Saha, "Modeling of electrical discharge machining process using back propagation neural network and multi-objective optimization using non-dominating sorting genetic algorithm-II," Journal of Materials Processing Technology, vol. 186, no. 1-3, pp. 154-162, 2007.

[11] S. Yang, J. Srinivas, S. Mohan, D. Lee, and S. Balaji, "Optimization of electric discharge machining using simulated annealing," Journal of Materials Processing Technology, vol. 209, no. 9, pp. 4471-4475, 2009.

[12] K. Deb, Optimization for Engineering Design Algorithms and Examples, Prentice Hall, New Delhi, India, 2004.

[13] R. T. Marler and J. S. Arora, "Survey of multi-objective optimization methods for engineering," Structural and Multidisciplinary Optimization, vol. 26, no. 6, pp. 369-395, 2004.

[14] T. W. Athan and P. Y. Papalambros, "A note on weighted criteria methods for compromise solutions in multi-objective optimization," Engineering Optimization, vol. 27, no. 2, pp. 155-176, 1996.

[15] S. Bandyopadhyay, S. Saha, U. Maulik, and K. Deb, "A simulated annealing-based multiobjective optimization algorithm: AMOSA," IEEE Transactions on Evolutionary Computation, vol. 12, no. 3, pp. 269-283, 2008.

[16] B. Suman and P. Kumar, "A survey of simulated annealing as a tool for single and multiobjective optimization," Journal of the Operational Research Society, vol. 57, no. 10, pp. 1143-1160, 2006.

[17] A. Suppapitnarm, K. A. Seffen, G. T. Parks, and P. J. Clarkson, "Simulated annealing algorithm for multiobjective optimization," Engineering Optimization, vol. 33, no. 1, pp. 59-85, 2000.

[18] P. Czyzak and A. Jaszkiewicz, "Pareto simulated annealing-a metaheuristic technique for multiple-objective combinatorial optimization," Journal of Multi-Criteria Decision Analysis, vol. 7, no. 1, pp. 34-47, 1998.

[19] N. Azizi and S. Zolfaghari, "Adaptive temperature control for simulated annealing: a comparative study," Computers \& Operations Research, vol. 31, no. 14, pp. 2439-2451, 2004. 

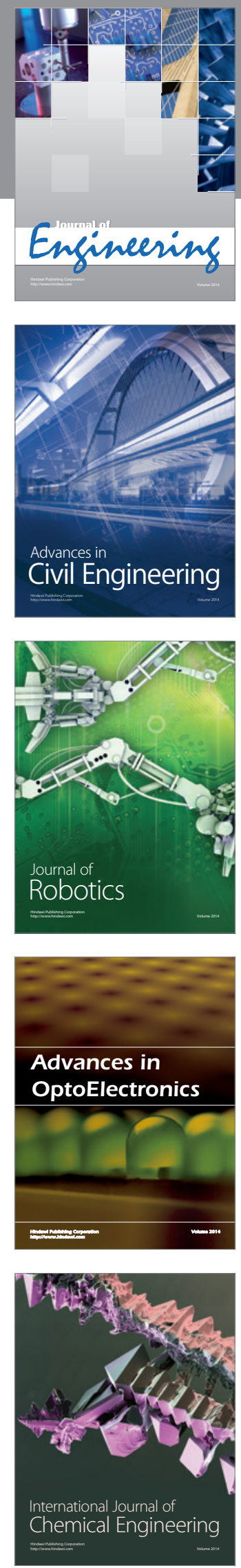

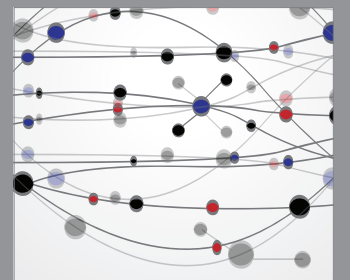

The Scientific World Journal
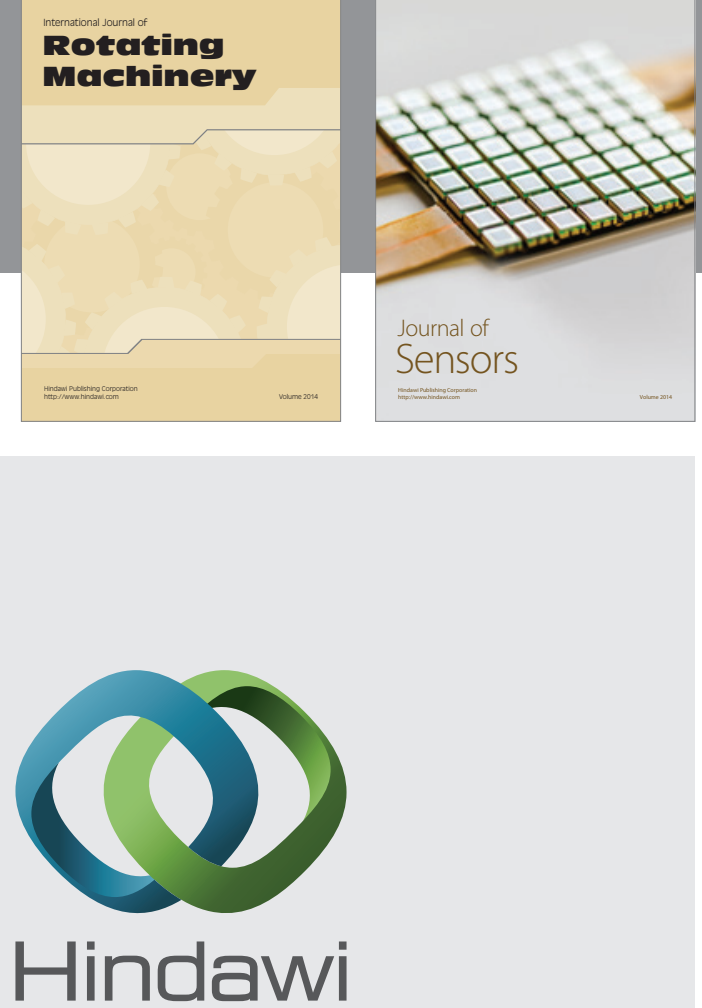

Submit your manuscripts at http://www.hindawi.com
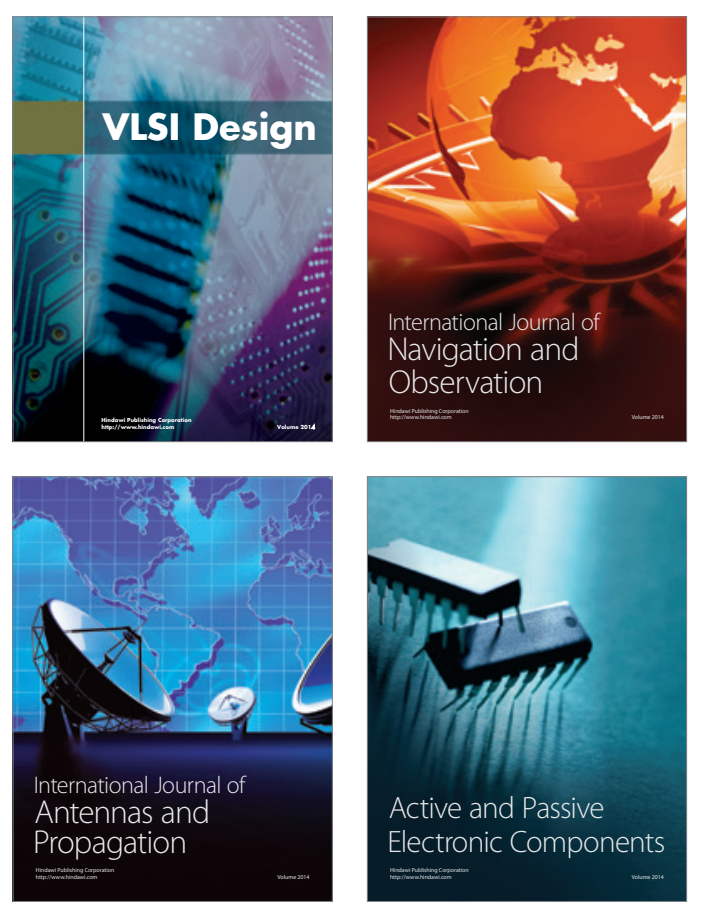
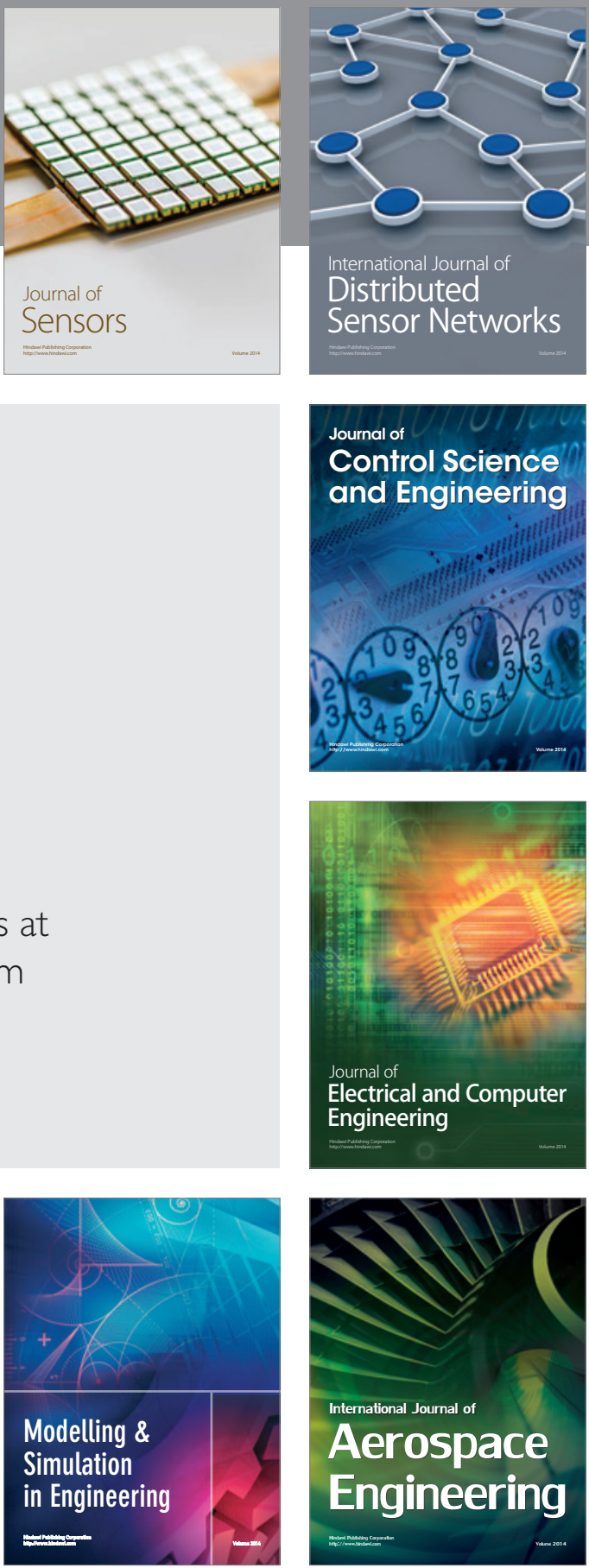

Journal of

Control Science

and Engineering
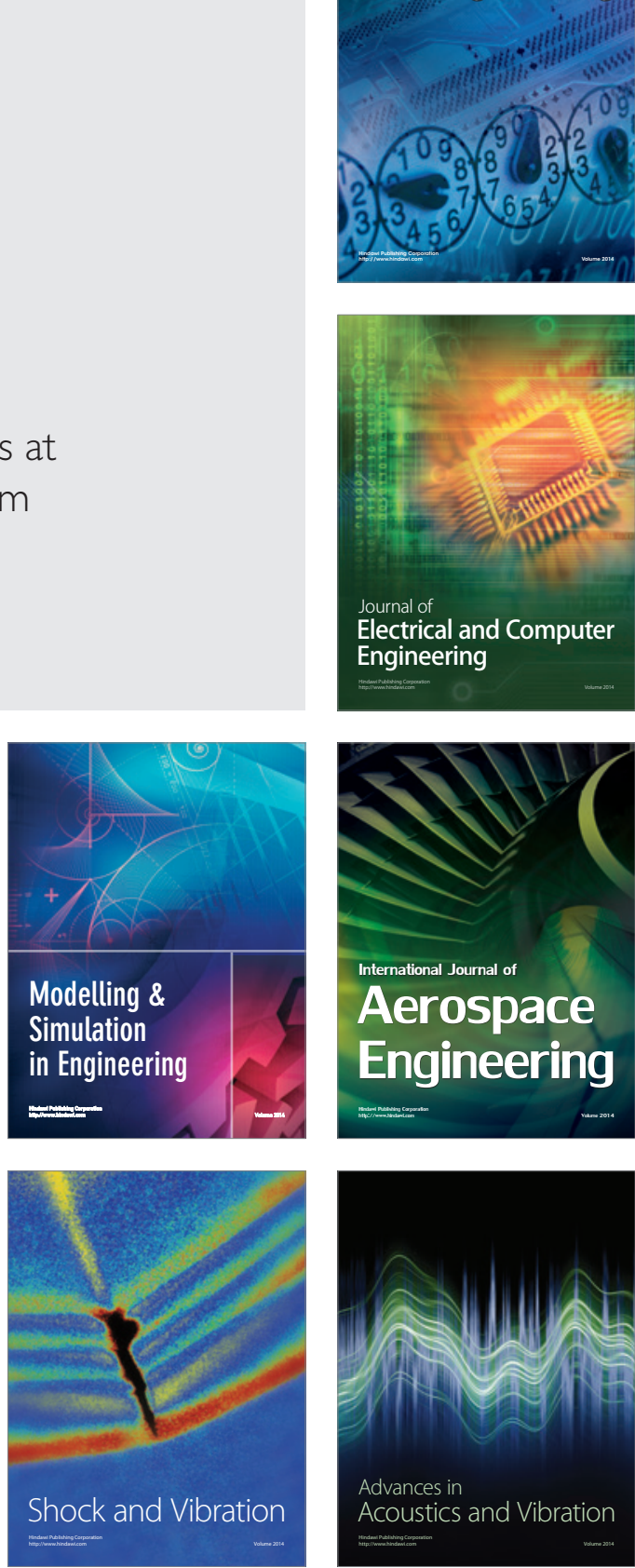